\title{
Partial remission in patient with Richter syndrome: an „emergency" treatment with pixantrone
}

\section{Paweł Szwedyk}

Department of Hematology and Internal Diseases,

Ludwik Rydygier Specialized Memorial Hospital, Cracow, Poland

Correspondence:

Pawet Szwedyk

Department of Hematology

and Internal Diseases,

Ludwik Rydygier Specialized Memorial Hospital, Cracow, Poland 31-826 Cracow, os. Złotej Jesieni 1 phone: 126468108 e-mail:pszwedyk@poczta.onet.pl

Received: 26.06.2020 Accepted: 30.06.2020

DOI: 10.24292/O1.OR.220300620.3 Copyright $\odot$ Medical Education. All rights reserved.

\section{ABSTRACT}

Chronic lymphocytic leukemia is the most commonly recognized type of leukemia in adults. The appearance of systemic symptoms such as weight loss, fever, or local symptoms in the form of rapidly growing organomegaly, lymphadenopathy in a patient with CLL raises the suspicion of transformation into a high-grade lymphoma - defined as Richter syndrome which is usually associated with very poor prognosis. The described case concerns a 71-year-old patient with this diagnosis, in whom due to the confirmed resistance to subsequent lines of immuno- and chemotherapy, an „emergency" treatment with a modern chemotherapy drug from the aza-anthracendion group - pixantrone was used. Treatment with pixantrone was associated with a relatively good response, translating into partial remission (also in the area of infiltrative changes in the head and neck structures), stabilization of the course of the disease and, consequently, allowed to extend the patient's life.

Key words: chronic lymphocytic leukemia, Richter syndrome, chemotherapy, immunotherapy, pixantrone 


\section{INTRODUCTION}

Chronic lymphocytic leukemia (CLL) is the most commonly recognized type of leukemia in adults. In most patients, the therapeutic goal is to achieve complete remission, increase its duration and overall survival. According to current guidelines, it is defined as monoclonal B-cell lymphocytosis, lasting at least 3 months, with a value exceeding $5 \times 10^{9} / \mathrm{l}$ or regardless of the amount of lymphocytosis in the presence of cytopenia in peripheral blood secondary to bone marrow involvement. Lymphocytosis clonality should be confirmed by fluorocytometry, including co-expression of $\mathrm{CD} 19+, \mathrm{CD} 20+, \mathrm{CD} 5+, \mathrm{CD} 23+$ and the presence of lambda or kappa light chains.

Chronic lymphocytic leukemia is an elderly disease (median around 60 years) often asymptomatic, slow and not requiring treatment for many years. The diagnosis is often established accidentally after peripheral blood counts. A strategy for treating CLL should be developed at the time of diagnosis, individually for each patient. It should take into account the patient's age and general condition, clinical stage of the disease based on the Rai or Binet classification and the presence of prognostic factors, including immunophenotypic and cytogenetic factors, and if available, molecular. Currently, the therapeutic process uses immuno-/polychemotherapy with rituximab, and recently more and more often new drugs acting in the mechanism of kinase inhibition, e.g. Bruton kinase - ibrutinib or bcl 2 inhibition - venetoclax [1, 2].

About $10 \%$ of patients with chronic CLL are diagnosed with Richter syndrome (RS), i.e. high-grade lymphoma, most commonly diffuse large B-cell lymphoma (DLBCL). The appearance of systemic symptoms such as weight loss, fever, or local symptoms in the form of rapidly growing organomegaly or limfadenopathy in a patient with CLL raises the suspicion of transformation into a high-grade lymphoma which is usually associated with very poor prognosis. Diagnosis of RS is difficult and is based on the dynamics of systemic and local symptoms [3, 4]. Each case requires verification by histopathological examination. This clinical condition was already described in 1928 by Maurice Richter, who presented a case of rapidly progressing organomegaly in a patient with CLL [5].

The term Richter syndrome was first used in 1964 by Lortholary et al. [6], defining the transformation of CLL into large cell lymphoma. Richter syndrome can occur regardless of the clinical course of CLL. The etiology of the syndrome is not entirely clear, as the most probable mention is infection with Epstein-Barr virus (EBV), genetic defects of leukemia cells (e.g. chromosome 12 trisomy and chromosome 11 anomalies, p53 suppressor gene mutations, loss of gene expression p27, increase in the number of copies of the C-MYC gene and decrease in expression of the A-MYB gene). There are conflicting reports in the literature regarding the effect of chemotherapeutics on the development of Richter syndrome. Some authors report the association of the use of fludarabine with an increased risk of this syndrome in patients being treated for CLL, while others deny this relationship [7, 8]. There is also little data on specific therapeutic guidelines. Treatment of RS is usually rescue, in which chemotherapy along with consolidation therapy in the form of autologous hematopoietic stem cell transplantation (auto-HSCT) is used. Prognosis in RS is bad, according to various researchers, patients survive for an average of 2-5 months, which is associated with a worse response to polychemotherapy [9].

In the patient's case described below, pixantrone was used after depletion of other immuno-/polytherapy lines. Pixantrone is a new anticancer drug that belongs to the anthracenedion group. Unlike registered anthracyclines (doxorubicin and others) and anthracenedions (mitoxantrone), pixantrone is only a weak inhibitor of topoisomerase II. In addition, unlike anthracyclines and anthracenedions, pixantrone directly alkylates DNA to form stable DNA addition compounds and leads to double strand breaks. In addition, due to the incorporation of the nitrogen heteroatom into the ring and the absence of ketone groups, pixantrone has less potential to produce reactive iron-binding oxygen species and to form alcohol metabolites that are thought to be responsible for the anthracycline cardiotoxic effects. Due to its unique structure, pixantrone had minimal cardiotoxic effects in animal models compared to doxorubicin and mitoxantrone.

The recommended dose is $50 \mathrm{mg} / \mathrm{m}^{2}$ pixantrone on days $1^{\text {st }}, 8^{\text {th }}$ and $15^{\text {th }}$ of each 28 -day cycle for up to six cycles $[10,11]$. It is indicated as monotherapy for the treatment of repeated or recurrent refractory, aggressive non-Hodgkin's B-cell lymphoma (NHL) in adults. Therapy with pixantrone is financed in Poland as part of the drug program since the turn of $2017 / 2018$. It is also used in chemotherapy regimens, e.g. P[R]EBEN (pixantrone, etoposide, bendamustine, rituximab). The most common side effects with (seen in more than 1 patient in 10) are: neutropenia, leukopenia and lymphopenia, thrombocytopenia, anemia, nausea, vomiting, change in skin color, hair loss, discoloration of urine and asthenia (weakness) [11].

\section{CASE REPORT}

66-year-old patient with a history of type 2 diabetes treated with insulin and well-controlled hypertension, was referred to the lo- 
cal Department for the treatment of lymphoproliferative disease. The final diagnosis was made on the basis of histopathological examination of the left axillary lymph node in November 2013 (chronic lymphocytic leukemia stage Binet B, RAI II). On physical examination peripheral nodal regions were involved (especially the inguinal and small pelvis) causing lymphatic stasis in the left lower limb accompanied by thrombosis. In addition, hyperleukocytosis reaching 100,000/ $\mu$ l, without significant cytopenia, general symptoms in the form of sweat, weight loss were present. Patient was treated with immunochemotherapy - two R-CVP cycles (rituximab, cyclophosphamide, vincristine, prednisone) in November and December 2013, with a transient, partial nodal response. Due to insufficient clinical response in January 2014, the therapy was changed - immunochemotherapy was performed according to the RFC light scheme (rituximab, fludarabine, endoxan) - a total of four cycles, achieving a good clinical response, similar to complete remission, with all nodal infiltrates resolving. Since then, he was observed in the Hematological Outpatient Clinic with hematologic remission. Unfortunately at the end of 2017 the progression in the form of increasing general symptoms and peripheral lymphadenopathy was observed.

In this situation for the purpose of diagnostics and possible modification of treatment he was reffered to the Hematology Department. On admission patient was in a moderate general condition with strongly expressed general symptoms (fever, sweats, weight loss) and pain in the lower limbs. No significant organomegaly was found. Peripheral lymph nodes were enlarged in all peripheral groups (packages up to $5 \mathrm{~cm}$ in all peripheral groups). In laboratory tests - elevated leukocytosis $(22.000 \mu \mathrm{l})$ with $70 \%$ lymphocytosis. In imaging examinations no significant pathology was found. A lymph node was taken for histopathological examination. After the initial treatment with steroids, another line of therapy was started - first RB regimen (rituximab, bendamustine) was given, without significant complications and good hematological response (partial regression of general symptoms and lymphadenopathy). After discharge from the hospital, another rapid nodal progression occurred in the neck, facial skull, right eyeball (including eyelid drooping and eyelid gap) with accompanying general symptoms. MRI of the orbit and brain showed extensive changes in the right paranasal sinuses, orbit and adjacent lymph nodes (fig. 1). In the obtained histopathological result of the previously collected lymph node, transformation from chronic lymphocytic leukemia to diffuse lymphoma from large B-DLBCL cells was found (Richter's transformation). From February $26^{\text {th }}, 2018$, intensive polychemotherapy was started - the first $\mathrm{R}$-CHOP regimen (rituximab, endoxan, vincristine, doxorubicin, prednisone) was given with a good clinical response (regression of peripheral lymphadenopathy and general symptoms). Granulocyte colony stimulating factor (GCS-F) filgrastim was also given during chemotherapy. In addition, lumbar puncture was performed with intrathecal administration of cytostatics (cerebrospinal fluid showed signs of involvement by the lymphoma process). In March 2018, with almost full nodal regression and resolution of oculomotor disorders, immunochemotherapy (second cycle of R-CHOP and intrathecal treatment) was continued. Additionally pegylated G-CSF and darbepoetin were administered without complications. A further six cycles of R-CHOP were given without complications.

FIGURE 1. MRI of the head revealing extensive infiltrative changes in the right paranasal sinuses, right eye socket and adjacent lymph nodes (February 2018).

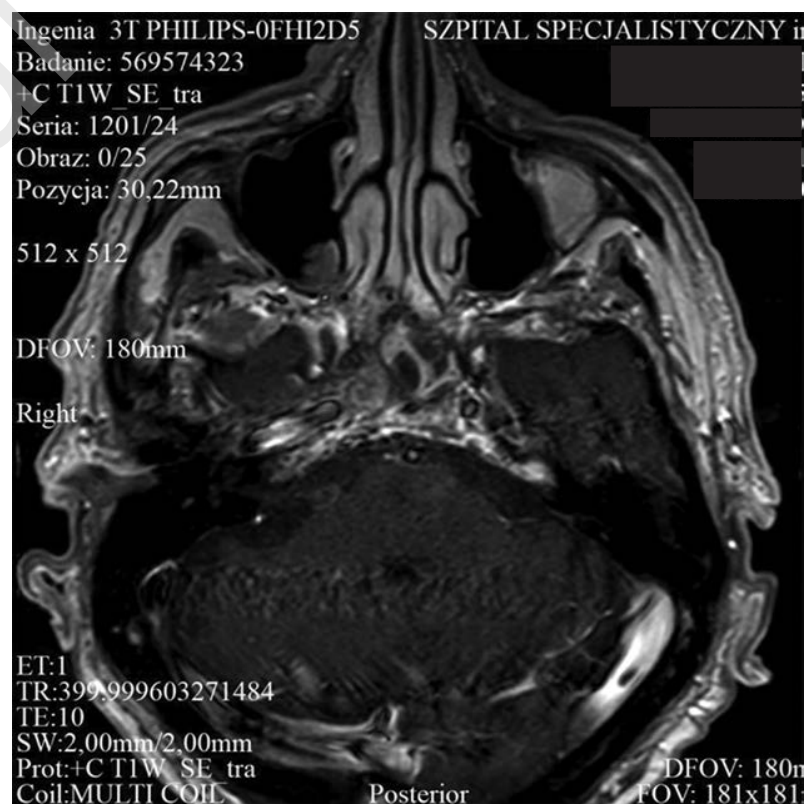

In July 2018 another progression in the craniofacial area was observed. During the next hospitalization an MRI of the brain and facial skeleton was performed, in which the progression of changes in the sinuses, orbit and ethmoidal air cells were found (fig. 2).

In July 2018, the next line of polychemotherapy - DHAP (cisplatin, cytarabine, dexamethasone) - was started in life indications, obtaining a good effect in the form of regression of peripheral lymphadenopathy. The patient required the use of G-CSF and darbepoetin, too. Finally, an improvement in the general condition and blood morphotic parameters was obtained. In outpatient PET examination, metabolic active changes were present in the range comparable to MRI, as well as on both sides of the diaphragm. In this situation, treatment was continued - the second DHAP cycle was given, resulting in partial regression of periph- 
FIGURE 2. Control MRI of the brain and facial skull with progression of changes in the paranasal sinuses, orbit and ethmoidal air cells (July 2018).

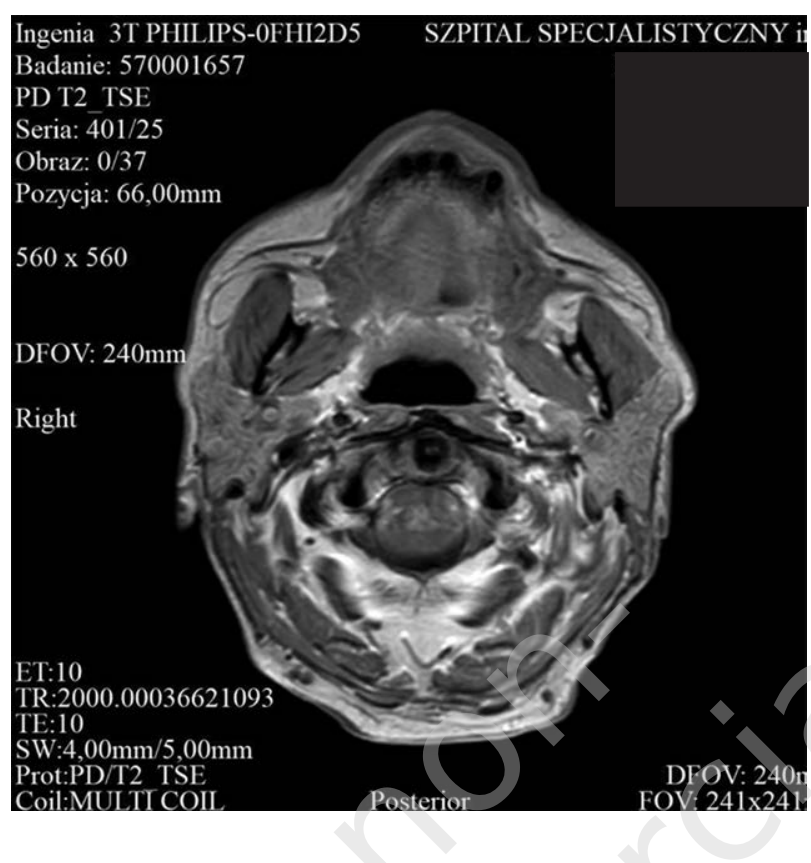

eral lymphadenopathy. In addition, the patient required re-support with G-CSF and erythropoietic hormone preparations.

In September 2018 with the features of the next progression in the form of the growth of peripheral lymphadenopathy, multiple skin nodules and general symptoms, the patient was re-admitted to the Hematology Department. Since this time, another therapy line using pixantrone as monotherapy was started in the classic administration regimen as described in the introduction. During pixantrone chemotherapy cytopenia, including grade third neutropenia, a relatively easily controlled with G-CSF, has been observed. The patient did not require any blood products during treatment. Unfortunately, during the breaks between cycles, infectious complications were present in the form of skin abscesses requiring targeted antibiotic therapy.

A total of four cycles of pixantrone were given until February 2019. Home stay was complicated by weakness and purulent infections around the buttocks. In February 2019, an MRI of the orbit and head was performed, showing significant improvement, partially meeting the criteria of partial remission for sinus and ethmoidal infiltrates, with remaining damage in the orbital bones (fig. 3). Pixantrone therapy was continued and after the fifth treatment cycle the patient was discharged home in good general condition.

In March 2019 he was admitted to the Hematology Department with a septic infection that was relatively easily controlled by
FIGURE 3. Control MRI of the head after pixantrone therapy - partial remission for sinus and ethmoidal infiltrates, with remaining damage in the orbital bones (February 2019).

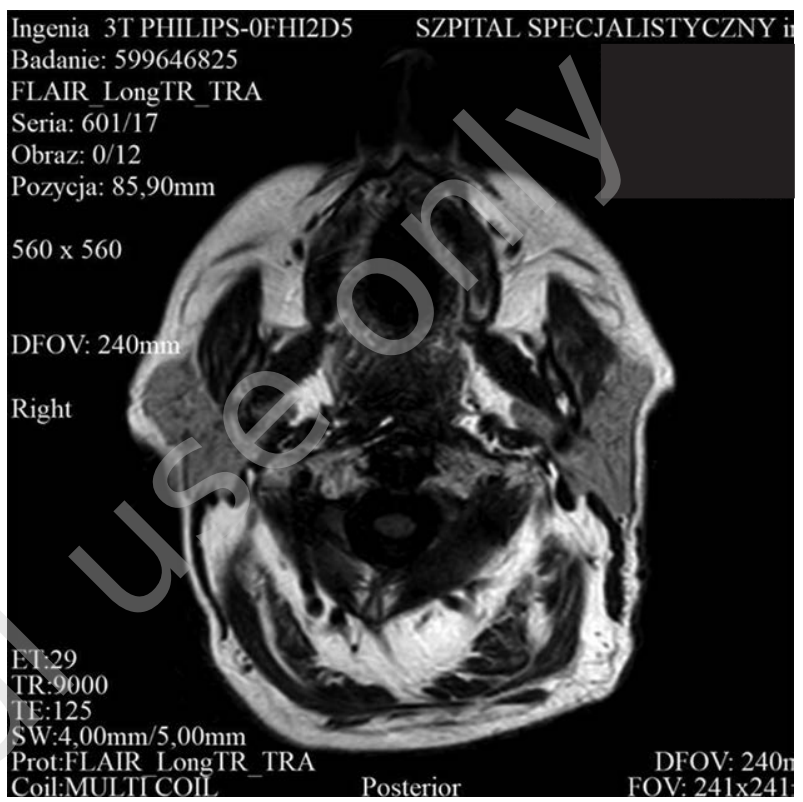

broad-spectrum antibiotic therapy and IVIG infusions. After the multidisciplinary consilium, it was decided to stop further chemotherapy.

In April 2019, rapid disease progression was observed in the form of an increase in general symptoms, lymphadenopathy in peripheral nodal structures. Due to the poor condition of the patient (3/4 according to WHO assessment) there was no further oncological treatment. After a short symptomatic therapy, the patient died at the end of April 2019.

\section{DISCUSSION}

In the described case of a patient with CLL and Richter syndrome, pixantrone treatment should be treated as a form of "rescue" treatment that has been used after all available forms of immuno- and chemotherapy have been exhausted. Despite the poor prognosis resulting from disease progression and the development of RS, pixantrone treatment allowed for partial disease remission, clinical stabilization and prolongation of the patient's life.

In the currently available literature, we have not found any reports regarding the beneficial effects of this modern chemotherapeutic agent concerning regression of lesions in the area of the central nervous system, which are found in the case of transformation of CLL towards diffuse lymphoma (DLBCL). 


\section{SUMMARY}

Pixantrone therapy was well tolerated by the patient, and the observed infectious complications most likely resulted from secondary immunodeficiencies in CLL and Richter syndrome, rather than from the haematological toxicity of this chemotherapeutic agent.
In the situation of very limited treatment options in cases of transformation of chronic lymphocytic leukemia into DLBCL, the described beneficial effect of pixantrone in a patient with RS creates a chance to improve the prognosis in this patient population.

\section{References}

1. Warzocha K. Przewlekła białaczka limfocytowa. Onkol Prak Klin. 2009; 5(2): 37-46.

2. Brown JR. How I treat CLL patients with ibrutinib. Blood. 2018; 131(4): 379-86.

3. Adamowicz K, Knopińska-Posłuszny W, Mital A et al. Transformacja przewlekłej białaczki limfocytowej w chłoniaka Hodgkina u chorego ze współistniejącym rakiem płuca. Onkol Prak Klin. 2008; 4(3): 110-3.

4. Deptala A, Asendrych A, Staszewska-Skurczynska M. Chemioimmunoterapia na bazie alemtuzumabu jest skuteczna w zespole Richtera i pozwala na uzyskanie długotrwałej regresji choroby. Opis przypadku. Acta Haematologica Polonica. 2009; 40(4): 917-22.

5. Richter MN. Generalized reticular cell sarcoma of lymph nodes associated with lymphocytic leukemia. Am J Pathol. 1928; 4(4): 285-92.

6. Lortholary P, Boiron M, Ripault P et al. Chronic lymphoid leukemia secondary associated with a malignant reticulopathy: Richter's syndrome. Nouv Rev Fr Hematol. 1964; 78: 621-44.

7. Pocock C, Matutes E, Wotherspoon A et al. Fludarabine therapy may precipitate large cell transformation in chronic lymphocytic leukemia but not in follicular lymphoma. Blood. 1998; 92: 429a (abstract 1774).

8. Tabateau S, Garidi R, Fernandes J et al. Fludarabine (FAMP) and risk of occurrence of Richter's syndrome among B-CLL. Blood. 2000; 96: 295b (abstract 5019).

9. Tsimberidou AM, O'Brien S, Khouri l et al. Clinical outcomes and prognostic factors in patients with Richter's syndrome treated with chemotherapy or chemoimmunotherapy with or without stem cell transplantation. J Clin Oncol. 2006; 24: 2343-51.

10. Pettengell R, Coiffier B, Egorov A et al. Long-Term Response and Remission with Pixantrone in Patients with Relapsed or Refractory Aggressive Non-Hodgkin Lymphoma: Post-Hoc Analysis of the Multicenter, Open-Label, Randomized PIX301 Trial. Clin Drug Investig. 2018; 38(6): 527-33. http://doi.org/0.1007/s40261-018-0635-3.

11. Péan $E$, Flores $B$, Hudson I et al. The European Medicines Agency review of pixantrone for the treatment of adult patients with multiply relapsed or refractory aggressive non-Hodgkin's B-cell lymphomas: summary of the scientific assessment of the committee for medicinal products for human use. Oncologist. 2013; 18(5): 625-33. 